\title{
Terrestrial gamma dose rates along one of the coastal highways in Sri Lanka
}

\author{
C.S. Sumithrarachchi and R. Hewamanna* \\ Department of Nuclear Science, University of Colombo, Colombo 03, Sri Lanka
}

\begin{abstract}
This study reports a van borne radiometric survey carried out along the A2 route to assess the annual radiation dose received by a commuter from Galle to Colombo using in-situ gamma spectrometry and a hand held environmental GM survey meter. A vehicle borne gamma spectrometric survey normally provides preliminary coverage of the radioelements in the top most part of the earth's crust. The ground concentrations of $\mathrm{K}$, Th and $\mathrm{U}$ were also obtained along the route. The daily equivalent dose calculated was $0.50 \mu \mathrm{Sv}$ in this route. The highest dose rates were measured from Kosgoda to Ambalangoda where activity concentrations of Th was around $0.30 \mathrm{~Bq} \mathrm{~g}^{-1}$. Activity concentration of $\mathrm{U}$ was the least and was not detected in many places along the route. Southern Province has an average outdoors-equivalent dose of $1.54 \mathrm{mSv} \mathrm{y}^{-1}$. The calculated dose along the A2 route was $0.12 \mathrm{mSv}$ for a commuter for 240 working days and gives the upper limit. This dose is about $10 \%$ of the average measured value for the Southern Province and is no more than a statistical variation of the natural background radiation.
\end{abstract}

\section{INTRODUCTION}

Gamma ray spectrometry survey is widely used to explore radioelements and to determine the ground concentrations of uranium thorium and potassium in the uppermost part of the earth's crust. This approach can also be used as a geological mapping tool and explore minerals. Health physicists can use total gamma radioactivity to obtain information on the distribution of radiation exposure rates due to environmental gamma rays from radionuclides in soil. Vehicle borne radiometric systems can be used effectively for an emergency response action due to a radiation contamination or accident.

\footnotetext{
${ }^{*}$ Corresponding author
} 
As gamma ray spectrometry can be used as a geological mapping tool the objective of the present study was to investigate the ground distribution of uranium, thorium and potassium and thereby to determine the radioactivity and secondly to assess the radiation dose received by a commuter from Galle to Colombo. The A2 route surveyed was selected on the basis of previous studies where radiation levels as high as $5.0 \mu \mathrm{Sv} \mathrm{h}{ }^{-1}$ had been recorded in a few locations along the Southern Coast ${ }^{(1)}$. These levels are related to the presence of higher concentrations of Th bearing monazite.

\section{METHODOLOGY}

All in-situ van-borne measurements presented in this study were carried out using a 2 in. $\varnothing$ x 2 in. NaI (Tl) detector connected with an Inspector System. The spectral data were stored in a computer and analysed using Genic PC and other mathematical software packages. The lower level discriminator of the $\mathrm{NaI}$ detector was set to $30 \mathrm{keV}$ for measurement of photon energies $30 \mathrm{keV}$ and above. The van-borne measurements were carried out in August 1999 and March 2000. The chosen route (A2) covered a total distance of $117 \mathrm{~km}$. No rain was encountered during both surveys. The NaI detector was placed in a passenger seat facing the floor and the van was driven at a speed close to 50 $\mathrm{km} \mathrm{h}^{-1}$ as the situation permitted and integration times lasting $300 \mathrm{~s}$ were initiated every $5 \mathrm{~min}$. The time taken for the journey was $182 \mathrm{~min}$. A hand held survey 6-80 type Mini instruments Environmental Meter (Burnham on Crouch, England) with a GM detector placed on the passenger seat was also used to obtain a preliminary coverage of the ground. A total of 36 in-situ measurements and 68 survey meter readings were collected. The shielding factor of the vehicle was determined separately using the hand held survey meter at various locations. Measurements were taken both inside and while walking around the vehicle.

The portable $\mathrm{NaI}(\mathrm{Tl})$ detector was calibrated for field in-situ measurements using the HASL method ${ }^{(2)}$. The calibration equation used is as follows ${ }^{(2)}$ :

$$
\frac{N}{A_{x}}=\frac{N}{N_{0}} \cdot \frac{N_{0}}{\varphi} \cdot \frac{\varphi}{A_{x}}
$$

where $N / A_{x}$ is the full energy peak count rate at energy $\mathrm{E}$ from a gamma transition of the radionuclide considered, $N / N_{0}$ is the angular correction factor for the detector response at energy $\mathrm{E}, N_{0} / \varphi$ is the peak response for a plane parallel beam of photons at energy $\mathrm{E}$ normal to the detector face and $\varphi / A_{x}$ is the fluence rate at energy $\mathrm{E}$.

Angular correction factors were selected on the basis of length to diameter ratio (1.0) of the detector crystal. The detector efficiency from gamma rays incident normal to the detector face were calculated using IAEA reference materials RGU-1 (U- ore), 
RGTh-1 (Th - ore) and RGK-1 $\left(\mathrm{K}_{2} \mathrm{SO}_{4}\right)$ contained in cylindrical containers with a radius of $4.2 \mathrm{~cm}$ and $2.0 \mathrm{~cm}$ height kept at a distance of $7 \mathrm{~cm}$ from the detector with a collimated shield for $10000 \mathrm{~s}$ each. The energy lines with a high abundance present in the ${ }^{238} \mathrm{U},{ }^{232} \mathrm{Th}$ and ${ }^{40} \mathrm{~K}$ were used to calculate the count rate. The fluence rates $(\varphi)$ of the photons at each of the energies identified were calculated by solving the following equation using numerical methods.

$$
\phi=\int_{0}^{h} \int_{0}^{R} \int_{0}^{2 \pi} \frac{\text { Aard } \theta . d r . d z}{4 \pi^{2} R^{2} h\left\{(h-z+d)^{2}+r^{2}\right\}}
$$

where $A$ is the activity of the standard, $R$ the radius of the container, $h$ is the height of the container, $d$ the distance between detector and source and $a$ is the emission probability. The fluence rates per unit activity at $1 \mathrm{~m}$ above ground were selected for natural radionuclides based on the assumption that they are distributed homogeneously in the ground. The field calibration was compared with the analyses of the laboratory gamma spectroscopy of soil samples collected from 6 different sites with different exposure rates.

\section{RESULTS AND DISCUSSION}

\subsection{Calibration for in situ measurements}

The angular correction factors selected varied from $0.99-0.96$ for the energy range $0.2-3.0 \mathrm{MeV}^{(3)}$. The calculated fluence rates (for a plane parallel beam of photons at a given energy normal to the detector face) for the above energy range varied from $0.025353-0.284675 \mathrm{~cm}^{-2} \mathrm{~s}^{-1}$. The selected fluence rates per unit activity concentration at $1 \mathrm{~m}$ above ground varied from $0.547-4.418 \mathrm{~cm}^{-2} \mathrm{~s}^{-1} \mathrm{~Bq}^{-1} \mathrm{~g}$ for the energy range $0.238-2.615 \mathrm{MeV}^{(4)}$. The in-situ and laboratory analyses for the activity concentrations of the radionuclides were within $5 \%$ and $10 \%$ for ${ }^{238} \mathrm{U}$ and ${ }^{232} \mathrm{Th}$ respectively. As such the calibration procedure adopted for the NaI was considered to be reasonable to use the $\mathrm{NaI}$ detector in field measurements. The NaI detector can be used for in-situ measurements where the gamma emitters are considered to be uniformly distributed, as would be the case for natural radionuclides.

The hand held surveymeter was used to confirm the observed trend of the in-situ measurements. Simultaneous measurements done using the two detectors showed a correlation coefficient of 0.93 (Fig.1). In view of this, the hand held survey meter was used to obtain the shielding factor of the vehicle, as it is lighter in weight and thus easier to carry around the vehicle. The shielding factor is a property of the vehicle and is independent of the detector used to measure it. A correlation curve with a correlation 
coefficient of 0.91 was obtained for outside and inside measurements from which the shielding factor of the vehicle was determined to be 1.40 .

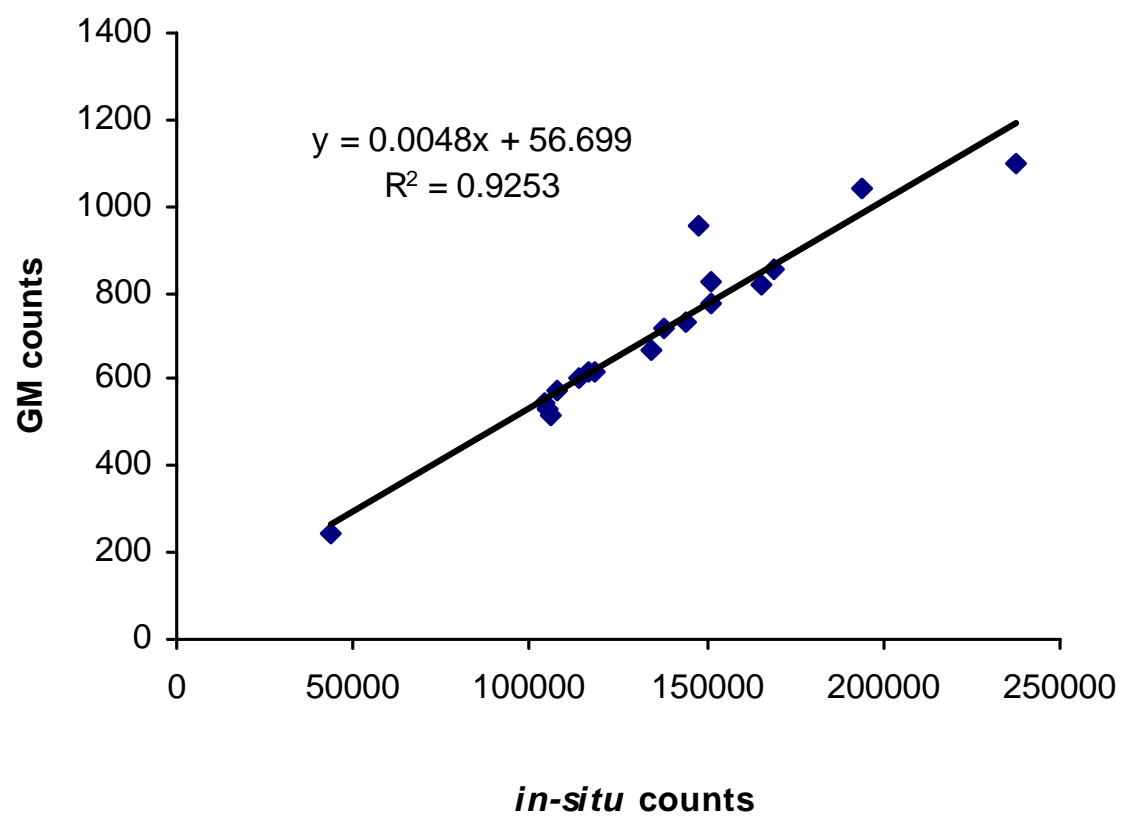

Fig. 1. A correlation between the GM survey meter and the in-situ system

Results of the radioelements present along the route studied are presented in Fig.2. Fig. 3 shows the distribution of absorbed dose rates in air due to terrestrial gamma radiation along the $\mathrm{A} 2$ route. The dose rates range from $65 \mathrm{nGy} \mathrm{h} \mathrm{h}^{-1}$ at Ratmalana to 237 nGy $\mathrm{h}^{-1}$ at Ambalangoda. The activity concentrations measured from in-situ measurements in these two areas were $0.04,0.86$ and $0.30,0.71 \mathrm{~Bq} \mathrm{~g}^{-1}$ for ${ }^{232} \mathrm{Th}$ and ${ }^{40} \mathrm{~K}$ respectively. This suggests that the contribution from ${ }^{232} \mathrm{Th}$ to the dose is greater than that from ${ }^{40} \mathrm{~K}$. ${ }^{238} \mathrm{U}$ (measured by the presence of the daughters) was below the detection limit $\left(0.023 \mathrm{~Bq} \mathrm{~g}^{-1}\right)$ at many of the measured locations. The total absorbed dose during a single journey would be $354 \mathrm{nGy}$ in $182 \mathrm{~min}$. The highest dose rates were measured from Kosgoda to Ambalangoda where activity concentrations of Th was around $0.30 \mathrm{~Bq} \mathrm{~g}^{-1}$. However, there are two areas along this route where higher dose rates were measured when the vehicle was stopped and in-situ spectroscopy was carried 


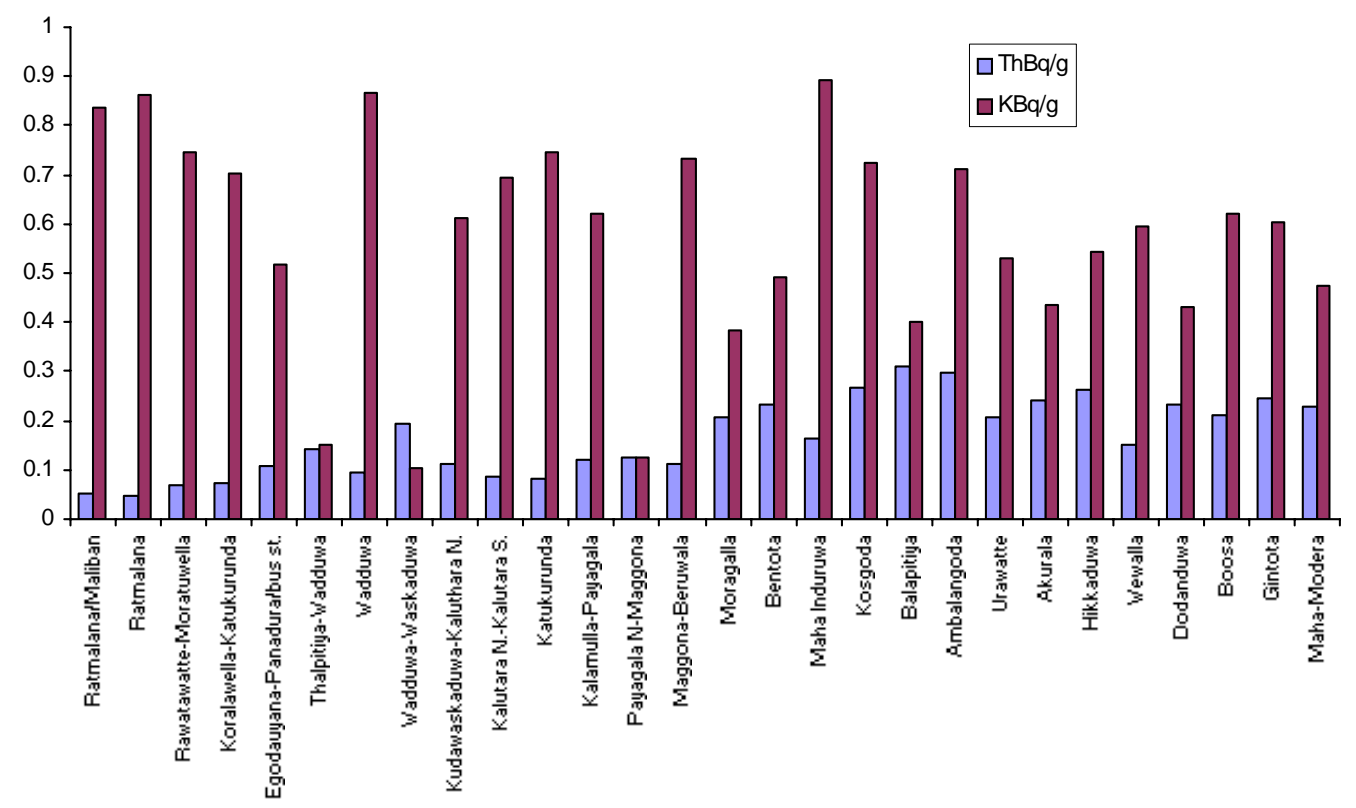

Fig.2. $\mathrm{K}$ and $\mathrm{U}$ activity measured with in-situ gamma survey along the A2 route

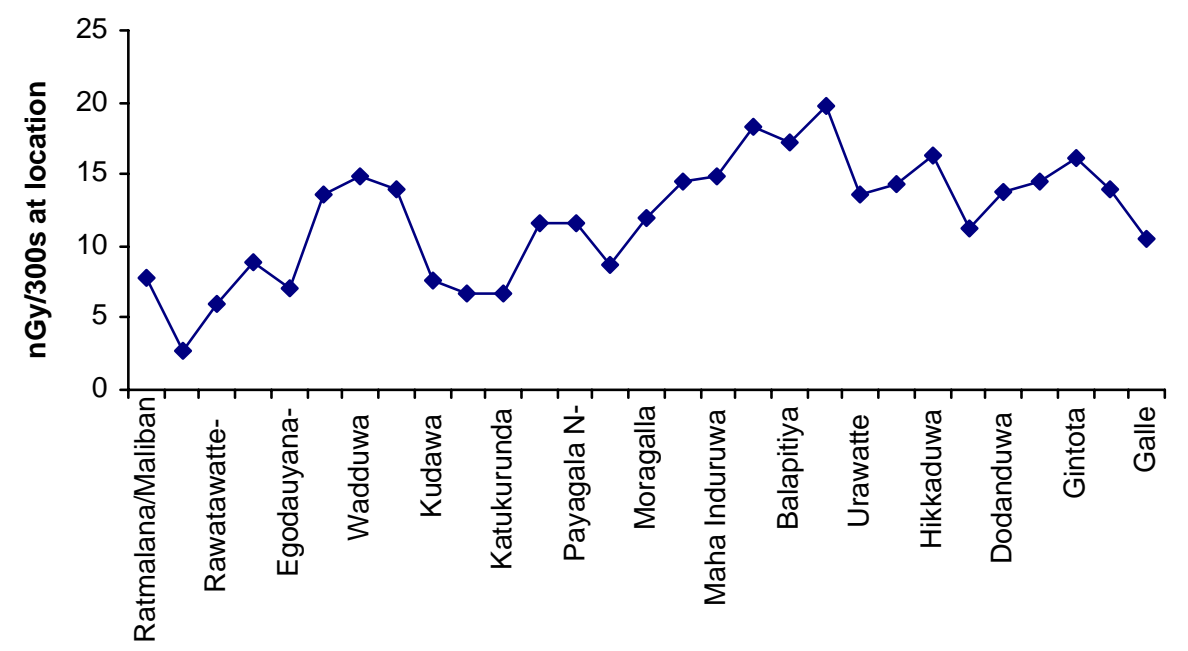

Fig.3 The absorbed dose along the A2 route

out outside the vehicle. They are Payagala North $300 \mathrm{nGy} \mathrm{h}{ }^{-1}$ and Kudawaskaduwa $277 \mathrm{nGy} \mathrm{h}^{-1}$. The dose rate measured while travelling in the vehicle in the said locations was $175 \mathrm{nGy}$. Surveys by direct measurements of dose rates have been conducted in many countries. For outdoor measurements where three fifths of the population of the 
world is represented national averages range from $24-160 \mathrm{nGy} \mathrm{h}^{-1}{ }^{(5)}$. Considering the number of working days for a year to be 240 the calculated equivalent dose received by a commuter from Galle to Colombo using in-situ gamma spectrometry was $0.12 \mathrm{mSv}$ for an year and gives the upper limit. The effective dose for adults was estimated using a $0.7 \mathrm{~Sv} \mathrm{~Gy}{ }^{-1}$ conversion factor ${ }^{(5)}$. Reported out door world values range from 1.47 - $9.8 \mathrm{mSv} \mathrm{y}^{-1}{ }^{(5)}$. Southern Province has an outdoor equivalent dose of $1.54 \mathrm{mSv} \mathrm{y}^{-1}$ (unpublished data). Although several anomalous locations with regard to the presence of high concentrations of Th had been monitored previously along the route under study, the equivalent dose received due to travelling in this route $(0.17 \mathrm{mSv})$ is about $10 \%$ of the average measured value for the Southern Province and is no more than a statistical variation of the natural background radiation.

\section{REFERENCES}

1. R.Hewamanna, R.A.G.Ranawake and C.M.Samarakoon, Gamma activity of plants from monazitebearing soils of the West Coast of Sri Lanka, Environmental \& Experimental Botany 27, No.4 449454, (1987)

2. H.L.Beck, J.A.DeCampo and C.V.Gogolak, In-situ Ge (Li) and NaI(Tl) gamma - ray spectrometer, HASL-258, (1972)

3. I.K.Helfer and K.M.Miller, Calibration factors for Ge detectors used for field spectrometry, Health Physics 55, 15-29 (1988)

4. Gamma-Ray Spectrometry in the Environment, International Commission on Radiation Units and Measurements (ICRU) Report 53 (1994)

5. UNSCEAR, United Nations Scientific Committee on the Effects of Atomic Radiation, Exposure from Natural Sources of Radiation. 1993 Report to the General Assembly. 93-828711 